\title{
Premedication for neonatal intubations: an unrecognized area for improvement
}

\begin{abstract}
Objective: Several academic societies have recommended premedication in neonatal intubation, but concerns have also been raised about associated adverse events. This study examined the rate of premedication, performance outcomes, and adverse events for non-urgent intubations in a Level 3 neonatal intensive care unit (NICU).

Method: The author reviewed all non-urgent intubations performed in a single Level 3 NICU from April 2011 through December 2012. The primary outcome was frequency of premedication use; secondary outcomes were intubation performance and adverse events.

Result: Of 103 non-urgent intubations, about half $(\mathrm{n}=52,51 \%)$ used premedication. The most frequently used medications were: atropine (92\%), fentanyl $(85 \%)$, and rocuronium $(61 \%)$. Infants receiving any premedication were larger and more mature. Intubation performance outcome and severe adverse events did not differ for intubations with or without premedication, except for higher incidence of hypercarbia in intubations with premedication ( $37 \%$ vs $11 \%, \mathrm{p}<0.03)$.
\end{abstract}

Conclusion: Recommendations regarding premedication in neonatal intubation were not consistently implemented, as is the case with many evidence-based practices. Further research is needed to evaluate the safety and medical need of premedication in preterm infants.

Keywords: premedication, neonate, non-urgent intubation
Volume 5 Issue 3 - 2018

\author{
Neetu Singh \\ Department of Neonatology, Dartmouth Hitchcock Medical \\ Center, Lebanon
}

Correspondence: Neetu Singh, Neonatology Division, Department of Pediatrics, Dartmouth Hitchcock Medical Center, I Medical Center Drive, NH 03756, Lebanon, Tel 603 650 4753, Email Neetu.Singh@hitchcock.org

Received: April 23, 2018 | Published: May 23, 2018
Abbreviations: NICU, neonatal intensive care unit; $\mathrm{PaCO}$, partial pressure of carbon dioxide; FRC, functional residual capacity

\section{Introduction}

Non-urgent endotracheal intubation is common in the neonatal intensive care unit (NICU). Previous studies have shown that conscious and awake intubations in neonates are painful and associated with adverse physiologic responses. ${ }^{1-5}$ Several trials have demonstrated that premedication significantly improves intubation conditions, decreases the time and number of attempts needed to complete the intubation procedure, and minimizes the potential for intubation related airway trauma $^{6-13}$ The Fetus and Newborn Committee of the American Academy of Pediatrics (2010) and Canadian Pediatric Society (2011) recommend premedication of infants before intubation when time permits. ${ }^{6,10}$ In addition, the International Evidence-Based Group for Neonatal Pain conclude that "tracheal intubation without the use of analgesia or sedation should be performed only for resuscitation in the delivery room or for life-threatening situations associated with the unavailability of intravenous access". ${ }^{14}$ Nevertheless, concerns have also been raised regarding adverse effects related to premedication for neonatal intubation. ${ }^{15}$

The purpose of this study was to examine the premedication practices in neonatal intubation and to compare intubation performance outcomes and incidence of adverse events with and without premedication in a Level 3 neonatal intensive care nursery (NICU). The primary outcome was the percent of non-urgent neonatal intubations receiving premedication (one or more of the following drugs for premedication: atropine (vagolytic), fentanyl (analgesic) and rocuronium (muscle relaxant)). Secondary outcomes were intubation performance and associated adverse events.

This retrospective cohort study in a single Level 3 NICU at the Dartmouth Hitchcock Medical Center, Lebanon, New Hampshire, USA, assessed the rate of premedication for non-urgent neonatal intubations, and compared performance and adverse effects of intubation with and without premedication. The Dartmouth Committee for Protection of Human Subjects approved the study. During the study period, the hospital did not have a written policy on premedication use for non-urgent intubations during this timeframe. Instead, an electronic order entry set for premedication, available to the medical providers, included atropine $(0.02 \mathrm{mg} / \mathrm{kg})$, fentanyl $(2 \mathrm{mcg} /$ $\mathrm{kg}$ ) and rocuronium $(0.25 \mathrm{mg} / \mathrm{kg})$. This procedure gave providers the option to choose one, two, or all three drugs listed or not give any premedication based on their individual preference.

Participants were infants admitted to the Dartmouth-Hitchcock NICU with a documented intubation procedure code obtained from the hospital data reporting system from April $1^{\text {st }}, 2011$ to Dec 31 $1^{\text {th }}$, 2012. The study excluded intubations performed in the resuscitation room, delivery room, during transport, in the operating room and those performed in emergent or urgent situations in the NICU. Chart reviews provided detailed information on each participant and each intubation encounter, which was defined as a non-emergent intubation of an infant in the NICU, regardless of the number of providers attempting intubation, until declared successful based on documented color change on colorimeter and presence of bilateral breath sound. 
The number of attempts required for successful intubation per intubation encounter was recorded as per the documentation in the medical record.

Measures included baseline patient characteristics (gestational age and birth weight, and age at intubation) intubation performance outcome (success with first attempt, median number of attempts for successful intubation and need for more than two attempts), and adverse events (minor events included bradycardia and oxygen desaturation and serious events included chest wall rigidity, difficult bag and mask ventilation, and need for chest compression) documented for each intubation encounter. Finally, pre-intubation and post-intubation blood gases (capillary or arterial) for each intubation encounter was also recorded to examine the incidence of hypercarbia $(\mathrm{PaCO} 2 \geq 65 \mathrm{mmHg}$ ) with intubation.

The author collected data from individual chart review from the EMR, reviewing each intubation procedure note to collect information on date of intubation, person performing intubation, use of premedication and type of medications ordered, number of attempts and the adverse events documented. The pre- and post-intubation blood gas values were obtained from review of laboratory results.

\section{Statistical analysis}

Mean or median with ranges and frequencies on demographic variables, intubation performance, and use of premedication summarized the study sample. Intubation performance and adverse events were compared for intubations with any premedication (any combination of atropine, atropine with fentanyl, atropine with morphine or atropine with fentanyl and rocuronium) to no premedication. To assess the effect of including a muscle relaxant (rocuronium) for premedication, a sub-group analysis compared intubation performance and adverse outcomes for premedication including rocuronium to those with premedication not including rocuronium. Statistical Student's t-test (or by Mann-Whitney U test for skewed data), ANOVA for the continuous variables, and Fisher's exact or Pearson's chi square test for binomial variables compared infants who received or did not receive any premedication. For all analyses, the $\mathrm{p}$-value was set at $\mathrm{p}<0.05$. Analysis used STATA 12 .

\section{Results}

Hospital records during the study period indicated that 59 infants received 103 non-urgent intubation encounters. The infants ranged from 25 weeks to 42 weeks gestational age at birth and had median birth weight of $1700 \mathrm{gm}$ (range $450-4140 \mathrm{gm}$ ). The most frequent reason for intubation was respiratory distress $(72 \%)$, followed by apnea $(14 \%)$, tube replacement for air leak $(6 \%)$, accidental extubation $(2 \%)$ and others $(6 \%)$.

Table 1 shows infant and intubator characteristics. Premedication occurred in $51 \%$ of 103 non-urgent intubation encounters. The mean gestational age and birth weight of the infants were significantly higher in the intubations with any premedication compared to intubations with no premedication. Medications used for premedication were: atropine, $(92 \%)$, fentanyl $(85 \%)$, and rocuronium $(61 \%)$. In one instance morphine was used instead of fentanyl. Residents were most likely to perform intubation with premedication $(76 \%)$, followed by nurse practitioners $(46 \%)$ and neonatologists $(20 \%)$.
The incidence of success on the first attempt did not differ for intubation with any premedication (46\%) compared to no premedication $(44 \%)[p=0.69]$. The median number of attempts for successful intubation and incidence of multiple attempts $(\geq 2)$ was also comparable in the two groups (Table 2). Table 3 shows that intubation performance (success with first attempt, median number of attempts and need for multiple attempts) was unrelated to type of medication (rocuronium versus other). Minor intubation complications, such as bradycardia and desaturations were reported in less than $20 \%$ of the procedures. The incidence of serious adverse effects, including need for chest compression and difficult bag and mask ventilation, was also unrelated to use of any premedication (Table 4). Further, the incidences of the adverse effects were not increased in intubations with premedication using rocuronium compared to those not using rocuronium.

Only two-thirds of intubation encounters had both pre-intubation and post-intubation blood gases available for evaluation of hypercarbia $\left(\mathrm{PCO}_{2} \geq 65 \mathrm{mmHg}\right)$. Intubations with any premedication were associated with a higher incidence of post-intubation hypercarbia [37 $\%$ vs $11 \%, p=0.03$ ] and had a larger difference between pre-intubation and post-intubation $\mathrm{PaCO}_{2}$ compared to those with no premedication [mean difference between the groups $-12.3 \mathrm{mmHg}$ (95\% CI: -21.2 , -3.4) $p=0.007]$ (Table 4). The incidence of post-intubation hypercarbia as well mean difference between pre-intubation and post-intubation $\mathrm{PaCO}_{2}$ was not significantly higher with premedication including rocuronium compared to premedication not including rocuronium.

Table I Infant and intubator characteristics

\begin{tabular}{llll}
\hline & $\begin{array}{l}\text { Any } \\
\text { Premedication }\end{array}$ & $\begin{array}{l}\text { No } \\
\text { Premedication }\end{array}$ & $\begin{array}{l}\text { p } \\
\text { value }\end{array}$ \\
\hline N (intubation episodes) & 52 & 51 & \\
BW (gm) & & & \\
Median, range & $1935(683,3710)$ & $1280(450,4140)$ & \\
Mean (SD)* & $2026(826)$ & $1569(925)$ & 0.02 \\
GA at birth (weeks) & & & \\
Median, range & $34(25,42)$ & $29(25,41)$ & \\
Mean (SD)* & $32.6(4.7)$ & $30.4(4.4)$ & \\
Age at intubation, days & $3(1,120)$ & $2(1,105)$ & \\
Premedication use based on Level of training of intubator, N & \\
RT & 0 & 2 & \\
Resident & 13 & 4 & \\
Fellow & 9 & 7 & \\
NNP & 29 & 34 & \\
Neonatologist & 1 & & \\
\hline
\end{tabular}

Table 2 Intubation performance

\begin{tabular}{llll}
\hline & $\begin{array}{l}\text { Any premedication } \\
\mathbf{N}=\mathbf{5 2}\end{array}$ & $\begin{array}{l}\text { No } \\
\text { premedication } \\
\mathbf{N = 5 1}\end{array}$ & $\begin{array}{l}\mathbf{p} \\
\text { value }\end{array}$ \\
\hline $\begin{array}{l}\text { Intubation on first } \\
\text { attempt }\end{array}$ & $46 \%$ & $44 \%$ & 0.82 \\
$\begin{array}{l}\text { Median attempts per } \\
\text { patient }\end{array}$ & $2(1,4)$ & $2(1,4)$ & \\
\begin{tabular}{l} 
Multiple attempts $(\geq 2)$ \\
\hline
\end{tabular} & $31 \%$ & $34.60 \%$ & 0.72 \\
\hline
\end{tabular}


Table 3 Intubation performance with premedication including rocuronium or no rocuronium

\begin{tabular}{llll} 
& $\begin{array}{l}\text { Premedication } \\
\text { including rocuronium } \\
\mathbf{N}=\mathbf{3 2}\end{array}$ & $\begin{array}{l}\text { Premedication not including } \\
\text { rocuronium N=20 }\end{array}$ & p value \\
\hline Intubation on first attempt & $53 \%$ & $35 \%$ & 0.2 \\
Median attempts per patient & $1(1,4)$ & $2(1,4)$ & 0.28 \\
Multiple attempts $(\geq 2)$ & $26 \%$ & $40 \%$ & \\
\hline
\end{tabular}

Table 4 Adverse effects of intubation with any premedication and no premedication

\begin{tabular}{|c|c|c|c|}
\hline & Any premedication & No premedication & P value \\
\hline Bradycardia (\%) & $10 \%$ & $10 \%$ & NS \\
\hline Desaturation (\%) & $17 \%$ & $10 \%$ & NS \\
\hline Chest Compression (n) & 0 & 0 & NS \\
\hline Difficult Bag and mask ventilation (n) & 2 & 2 & NS \\
\hline $\begin{array}{l}* \text { Post-intubation hypercarbia }(\mathrm{PaCO} 2 \geq 65 \\
\mathrm{mmHg})(\%)\end{array}$ & $37 \%$ & $11 \%$ & 0.03 \\
\hline $\begin{array}{l}\text { Mean difference (SD) between pre-intubation } \\
\text { and post-intubation } \mathrm{PaCO} 2\end{array}$ & $2.6(19)$ & $-9.7(17.65)$ & 0.007 \\
\hline
\end{tabular}

*Statistically significant [Fisher Exact or Pearson's Chi square test for binomial variable and t-test or Mann-Whitney rank sum test for continuous variable]

\section{Discussion}

This study found inconsistent utilization of premedication for neonatal intubation in a level 3 NICU. Premedication was given in half of all non-urgent intubations, only two-thirds of whom received a muscle relaxant. Both patient characteristics (weight) and practitioner characteristics (level of training and profession) predicted variation in practice. Infants who were larger and more mature were more likely to receive premedication. Residents and nurse practitioners were more likely to use premedication than neonatologists. Neither the intubation performance nor the incidence of serious adverse events differed for intubations with or without premedication. Hypercarbia was, however, more likely after intubations using premedication.

One interpretation of this study is that professionals, especially neonatologists, are reluctant to accept expert recommendations regarding an evidence-based practice. This reluctance could be due to unanswered concerns regarding the practice of premedication in newborns, such as the ideal pharmaceutical drug for sedation and muscle relaxation, the dose of these medications to be used in preterm infants, and the long-term benefits or adverse effects. Professionals' discomfort with premedication may be more pronounced for very small, extremely preterm infants because of the lack of data for this special population. The unexpected finding of increased incidence of post-intubation hypercarbia with premedication needs further study. Multiple factors could cause post-intubation hypercarbia: the loss of spontaneous respiratory drive and functional residual capacity following muscle paralysis and sedation from the drugs, inadequate ventilation during the intubation procedure itself, or insufficient ventilator support after intubation.

The results of this study resonate with other studies in the U.S.: less than half of teaching hospitals consistently use premedication for non-urgent intubations, ${ }^{16}$ only one-third of neonatologists frequently use premedication, and less than half of the institutions have written protocols on the use of premedication. ${ }^{17}$ The U.S. practices contrast with data from the U.K., Canada, Australia and New Zealand, which report a much higher usage of premedication $(93 \%-100 \%)$ in neonates, and in particular, the use of muscle relaxant for premedication (78$93 \%)^{18-20}$
Fear of adverse events has been proposed as the main barrier to universal use of premedication in neonates. ${ }^{10}$ Similar to this study, however, neither randomized control trials nor observational studies have reported any significant increase in serious adverse events with the use of premedication. ${ }^{9,11,21}$ An incidence of $4.3 \%$ for chest wall rigidity and one case of morphine overdose was reported in a prospective study of premedication in neonates..$^{15}$ Another prospective study reported an incidence of $3.3 \%$ for difficult bag and mask ventilation associated with fentanyl use, which was often reversed with administration of muscle relaxant. ${ }^{22}$ Serious adverse events associated with premedication appear to be preventable or at least reversible.

The high incidence of post-intubation hypercarbia with premedication in this study has not been reported previously. If validated, it may have significant implications for extremely preterm infants because of the increased risk of intraventricular hemorrhage with severe hypercarbia and its associated neurodevelopmental squelae. ${ }^{23-26}$ This adverse event could be prevented with appropriate attention to adequate ventilation before, during and after intubation. Also, using a short-acting muscle relaxant such as succinylcholine may also prevent such adverse effects by reducing the time to the onset of spontaneous breathing after paralysis.

Several limitations of the current study, mostly inherent in the retrospective study design in a single center, deserve mention. First, the data were collected by chart review, with potential for inaccurate documentation (such as inconsistency in defining an intubation attempt, lack of documentation of minor adverse events such as bradycardia and desaturation). Second, effect of premedication may have been underestimated because the measure of intubation performance did not include factors such as degree of cord visualization, decrease in pain and patient discomfort, and hemodynamic stability. Third, the results of hypercarbia with premedication should be interpreted with caution because blood gases were not obtained promptly before and after intubation procedure (but often within an hour of intubation, as per unit protocol). Also, data on the initial ventilator support following intubation were not included in the analysis. A final limitation was the small sample size and sole use of univariate analyses to compare 
groups, which might not detect confounding variables.

In conclusion, the current study shows inconsistent utilization of premedication during non-urgent neonatal intubations, particularly for very small infants, despite expert recommendations. Delay in acceptance of evidence-based practices is common in general medicine and appears to occur in the NICU setting also. Perhaps further research could allay professionals' concerns regarding the potential adverse effects of premedication, particularly in the small preterm infants. The finding of higher incidence of post-intubation hypercarbia with premedication has not been reported previously and needs further study. It may represent inadequate maintenance of functional residual capacity after sedation and paralysis with premedication, particularly with use of long-acting muscle relaxants, and emphasizes the need for adequate ventilation during the intubation procedure and use of short acting muscle relaxant.

\section{Acknowledgments}

None.

\section{Author contributions}

The author has contributed in the following manner: Dr. Singh conceptualized and designed the study, drafted the initial manuscript, and approved the final manuscript as submitted.

\section{Conflict of interest}

Authors declare there is no conflict of interest.

\section{References}

1. Barrington KJ, Finer NN, Etches PC. Succinylcholine and atropine for premedication of the newborn infant before nasotracheal intubation: a randomized, controlled trial. Critical care medicine. 1989;17(12):1293-1296.

2. Friesen RH, Honda AT, Thieme RE. Changes in anterior fontanel pressure in preterm neonates during tracheal intubation. Anesthesia \& Analgesia. 1987;66(9):874-878.

3. Kelly MA, Finer NN. Nasotracheal intubation in the neonate: physiologic responses and effects of atropine and pancuronium. The Journal of pediatrics. 1984;105(2):303-309.

4. Pokela ML, Koivisto M. Physiological changes, plasma $\beta$-endorphin and cortisol responses to tracheal intubation in neonates. Acta Paediatrica. 1994;83(2):151-156.

5. Shribman A, Smith G, Achola K. Cardiovascular and catecholamine responses to laryngoscopy with and without tracheal intubation. British Journal of Anaesthesia. 1987;59(3):295-299.

6. Barrington KJ. Premedication for endotracheal intubation in the newborn infant. Paediatrics \& child health. 2011;16(3):159-164.

7. Carbajal R, Eble B, Anand KJ. Premedication for tracheal intubation in neonates: confusion or controversy? Semin Perinatol. 2007;31(5):309-317.

8. Dempsey EM, Al Hazzani F, Faucher D, et al. Facilitation of neonatal endotracheal intubation with mivacurium and fentanyl in the neonatal intensive care unit. Arch Dis Child Fetal Neonatal Ed. 2006;91(4):F279F282.
9. Feltman D, Weiss M, Nicoski P, et al. Rocuronium for nonemergent intubation of term and preterm infants. Journal of Perinatology. 2011;31(1):38-43.

10. Kumar P, Denson SE, Mancuso TJ. Premedication for nonemergency endotracheal intubation in the neonate. Pediatrics. 2010;125(3):608-615.

11. Lemyre B, Doucette J, Kalyn A, et al. Morphine for elective endotracheal intubation in neonates: a randomized trial [ISRCTN43546373]. BMC Pediatr. 2004;4:20.

12. Pereira e Silva Y, Gomez RS, Marcatto Jde O, et al. Morphine versus remifentanil for intubating preterm neonates. Arch Dis Child Fetal Neonatal Ed. 2007;92(4):F293-F294.

13. Roberts KD, Leone TA, Edwards WH, et al. Premedication for nonemergent neonatal intubations: a randomized, controlled trial comparing atropine and fentanyl to atropine, fentanyl, and mivacurium. Pediatrics. 2006;118(4):1583-1591.

14. Anand KJ. Consensus statement for the prevention and management of pain in the newborn. Arch Pediatr Adolesc Med. 2001;155(2):173-180.

15. Venkatesh V, Ponnusamy V, Anandaraj J, et al. Endotracheal intubation in a neonatal population remains associated with a high risk of adverse events. Eur J Pediatr. 2011;170(2):223-227.

16. Sarkar S, Schumacher RE, Baumgart S, et al. Are newborns receiving premedication before elective intubation? J Perinatol. 2006;26(5):286-289.

17. Muniraman HK, Yaari J, Hand I. Premedication Use Before Nonemergent Intubation in the Newborn Infant. Am J Perinatol. 2015;32(9):821-824.

18. Kelleher J, Mallya P, Wyllie J. Premedication before intubation in UK neonatal units: a decade of change? Arch Dis Child Fetal Neonatal Ed. 2009;94(5):F332-F335.

19. Wheeler B, Broadbent R, Reith D. Premedication for neonatal intubation in Australia and New Zealand: a survey of current practice. J Paediatr Child Health. 2012;48(11):997-1000.

20. Whyte S, Birrell G, Wyllie J. Premedication before intubation in UK neonatal units. Arch Dis Child Fetal Neonatal Ed. 2000;82(1):F38-F41.

21. Simon L, Trifa M, Mokhtari M, et al. Premedication for tracheal intubation: a prospective survey in 75 neonatal and pediatric intensive care units. Crit Care Med. 2004;32(2):565-568.

22. Lemyre B, Cheng R, Gaboury I. Atropine, fentanyl and succinylcholine for non-urgent intubations in newborns. Arch Dis Child Fetal Neonatal Ed. 2009;94(6):F439-F442.

23. Fabres J, Carlo WA, Phillips V, et al. Both extremes of arterial carbon dioxide pressure and the magnitude of fluctuations in arterial carbon dioxide pressure are associated with severe intraventricular hemorrhage in preterm infants. Pediatrics. 2007;119(2):299-305.

24. Kaiser JR, Gauss CH, Pont MM, et al. Hypercapnia during the first 3 days of life is associated with severe intraventricular hemorrhage in very low birth weight infants. J Perinatol. 2006;26(5):279-285.

25. Koksal N, Baytan B, Bayram Y, et al. Risk factors for intraventricular haemorrhage in very low birth weight infants. Indian $J$ Pediatr. 2002;69(7):561-564.

26. Zayek MM, Alrifai W, Whitehurst RM, et al. Acidemia versus hypercapnia and risk for severe intraventricular hemorrhage. Am J Perinatol. 2014;31(4):345-352. 